\title{
Agricultural Diffuse Pollution and the EU Water Framework Directive: Problems and Progress in Governance
}

\author{
Daan Boezeman ${ }^{1,2, *}$, Mark Wiering ${ }^{1}$ and Ann Crabbé ${ }^{3} \mathbb{D}$ \\ 1 Department Geography, Planning and Environment, Institute for Management Research, \\ Radboud University, 6500 HK Nijmegen, The Netherlands; m.wiering@fm.ru.nl \\ 2 PBL Netherlands Environmental Assessment Agency, 2500 GH The Hague, The Netherlands \\ 3 Centre for Research on Environmental and Social Change (CRESC), University of Antwerp, \\ Sint-Jacobstraat 2, 2000 Antwerp, Belgium; ann.crabbe@uantwerpen.be \\ * Correspondence: d.boezeman@fm.ru.nl; Tel.: +31-6-11704966
}

Received: 26 August 2020; Accepted: 15 September 2020; Published: 16 September 2020

\begin{abstract}
Progress has been made on improving Europe's water quality. Nevertheless, there is much scepticism as to whether the goals of the European Water Framework Directive will be realised by 2027. Addressing diffuse agricultural sources of pollution remains a persistent problem. The Special Issue "Water Quality and Agricultural Diffuse Pollution in Light of the EU Water Framework Directive" aims to advance the understanding of the different governance arrangements European Member States developed to address this problem. The contributions in this Special Issue focus on governance arrangements in Denmark, England, Flanders/Belgium, Germany, Ireland, Poland, The Netherlands, Norway and Scotland. The contributions address three themes. First, the contributions signal serious concerns with policy integration across policy domains. Second, it appears to be tough to prioritise source-based measures over effect-based measures of all sorts despite the principles embedded in the Directive. Third, scientific knowledge is an important ally for water interests, yet politicisation in power struggles looms. The contributions in the Special Issue offer reflections on the open, participatory, experimentalist governance that the WFD exemplifies. While most authors agree that this path is attractive and appropriate in some respects, questions can be raised as to whether it also avoids confrontations and hampers the effectiveness of policies.
\end{abstract}

Keywords: water framework directive; agriculture; nutrients; diffuse pollution; governance; comparative policy; policy instruments; policy Integration; source-bases measures; science-policy interface

\section{Agricultural Diffuse Pollution and the Water Framework Directive: The Elephant in the Room?}

All over Europe, Members States are trying to improve the quality of water in order to achieve clean and healthy rivers, lakes, estuaries, coastal waters, and ground water. Central to achieving this ambition is the EU Water Framework Directive (WFD/2000/60/EC). This regulatory framework asks European Member States to set up plans for river basins, thereby following units that are close to geographical and hydrological boundaries and are sometimes crossing administrative borders. The WFD focuses on the quality of waters for humans and for ecosystems, including the protection of drinking and bathing water as well as the preservation and improvement of the aquatic ecology and the protection of species and habitats.

Progress has been made on improving Europe's water quality. Nevertheless, there is still much scepticism as to whether Member States will succeed in realising all the goals of the WFD by 2027. During the first WFD cycle, which ran from 2009 to 2015, the number of surface water bodies in 
"good" state only increased by $10 \%$ [1]. At this moment, around $40 \%$ of the European surface waters are in a good ecological status or potential and $38 \%$ have a good chemical status [2]. Even though these percentages are not low, many practitioners and observers claim that it is unrealistic to expect that good ecological status will be realised in all waters by 2027 [3]. With the second river basin management plans now being implemented and the third and, for now, last round of river basin plans being prepared, Member states are requested by the European Commission to step up their pace [4].

While addressing diffuse agricultural sources is critical to realising the ambitions, comparative governance literature on the WFD has focused on, e.g., stakeholder participation [5,6], formal implementation $[7,8]$ or the politics of exemptions [9], while the different approaches through which the Member States address diffuse agricultural sources in the practical implementation of the WFD remain underexplored. This is remarkable given the fact that European water law usually does not provide the policy tools to target these sources directly $[10,11]$ and Member States have to determine for themselves how their (domestic) policy fields and preferred governance approaches will deal with WFD obligations. This Special Issue entitled "Water Quality and Agricultural Diffuse Pollution in Light of the EU Water Framework Directive" tackles these comparative governance issues head on. Some countries are consciously looking for integration and collaboration in their design of policies, while others have separate and fragmented programmes and institutions. Some countries develop specific and differentiated area-based policies, while others prefer general, national policies. It is important to understand these differences in Member States, their efficacy as well as the inspiration and opportunities they might bring for other territories. This is, on the one hand, underscored by the ongoing process of "renationalisation" of the Common Agricultural Policy [12], with expanding possibilities and responsibilities of Member States in their agri-environmental policies. On the other hand, the 2019 "fitness check" of the WFD underlined the coherence challenges of water quality with agricultural policies and practices [13]. Diffuse sources remain one of the main pressures of surface waters [2]. Hence, agricultural diffuse pollution seems to be the elephant in the room for realising the ambitions of the Water Framework Directive.

The collection of articles in this Special Issue aims to advance the understanding of how Member States are dealing with the relationship between water quality and diffuse pollution and what governance arrangements have emerged in EU Member States. These insights are valuable input for the third round of river basin planning and the emerging discussions of post-2027 water governance. Central questions for this Special Issue are as follows: how are countries in Europe dealing with the problem of nutrients from diffuse agricultural sources in water and what kind of measures do they take? What modes of governance have emerged around these issues? How can these approaches be evaluated?

\section{Overview of the Articles}

In order to frame the theoretical focus of this Special Issue, Wiering, Boezeman and Crabbé [14] review the scholarly literature on the governance of diffuse agricultural sources in relation to the WFD. Their contribution looks at both central issues in the process of governing diffuse agricultural sources as well as the output of that process, i.e., the implementation of policy instruments. The WFD embeds various principles to inform the governance of diffuse pollutants. Wiering et al. [14] take three of those principles as their starting points to unbracket the literature. The design of the Directive should provide further integration of policy areas, environmental damage should be rectified at source and Member States are to take account of scientific and technical data to ground a systematic and comparable basis for programmes of measures. These three issues-integration and fragmentation, source- and effect-based measures and the intricacies of knowledge production-have repercussions for the organisation of governance related to the WFD and therefore function as the main themes for comparison in this Special Issue.

- Key to the first issue of fragmentation and the distribution of power to address diffuse sources is that the Directive stipulates how plans and policies are to be made, but in itself does not provide 
additional policy instruments to address diffuse sources. The literature underscores that most Member States adapted their traditional administrative structures and procedures only slightly to the WFD, leading to significant barriers to multi-sector integration. The agricultural domain is one of the domains in which integration is particularly insufficient. Nevertheless, the academic debate is ongoing whether further mainstreaming or more dedicated organisational structure is needed for effective policy-making.

- Regarding the second issue of source-oriented and effect-oriented measures, the literature presents evidence that Programmes of Measures often target symptoms rather than causes of water degradation. The measures taken under, e.g., the Nitrates Directive are most often insufficient to realise the water quality corresponding to a Good Ecological Status/Potential. The political unwelcomeness of interventions that affect agricultural incomes leads to the dominance of voluntary programmes and technical effect-based measures, which both rely on public funding.

- Regarding the third issue-knowledge-for-policies to address diffuse sources-the literature focusses on knowledge use and non-use as well as new forms of knowledge production. Central to this literature is the claim that "better" knowledge in itself does not resolve problems of controversy or delay around policies. The hierarchical model, which relies heavily on scientific expertise, can face serious difficulties. However, the institutional innovations such as joint fact finding or participatory monitoring have experienced varying degrees of success.

The three issues inherent in the governance of agricultural sources under the WFD have repercussions for the (potential) policy outcomes of governance. Wiering et al. [14] provide an overview of potential instruments to address diffuse sources and conclude that Member States developed various voluntary approaches on top of regulatory instruments. Notwithstanding their potential role, evidence is lacking about the conditions under which they can deliver effective and efficient outcomes. Additionally, there is evidence of shortcomings in effectiveness, pointing to problems with non-participation, cost-issues and misalignment of voluntary programmes with regulatory policies.

In her contribution on Norway, Hovik [15] explains how river basins have been made the basis for coordination of sectoral policies. At the level of newly introduced units of river basin districts and sub-districts, cross-sectoral and multi-level networks formulate Programmes of Measures. Nevertheless, this structure is additional and clearly subordinated to the pre-existing sectoral organisation and hierarchical steering. Formal powers remain within each policy sector. Hence, the WFD goals must be mainstreamed in the goal structure and policy programmes of these sectoral domains. The responsibilities for combating eutrophication is divided and fragmented between different sectors and governmental levels. Hovik concludes that even though the WFD goals of a Good Ecological Status have been integrated in the objectives of the Norwegian agricultural programme, changes in instrument choice or target setting have only been minor. The agricultural sector's response to diffuse pollution is dominated by voluntary and market-based instruments, as the substance of the Regional Environmental Programme makes clear. Despite the seeming consensus between the actors involved, regarding the efforts of the agricultural sector being too low and instruments too weak, changes towards other types of policy instruments are lacking. The dominant logic within the agricultural domain strongly influences instrument choice, which is facilitated by fragmentation, the corporatist tradition and the primacy of sectoral interests.

De Vito, Fairbrother and Russel [16] report on a comparative case study of England and Scotland. These authors focus on the issue of policy integration and the holistic approach envisioned by the WFD. They use the dimensions of cooperation, consistence, and salience to analyse the implementation of the Directive in their two cases. Central to their paper is the claim that more holistic and integrated governance approaches can result in the adoption of different policy mixes. Scotland's joined-up governance structure enabled cooperation and trust between policymakers and interest groups. This facilitated the adoption of a stricter policy package to address diffuse agricultural pollution, whose salience was enhanced by more consistent political commitment. The institutional fragmentation that characterised England functioned as a barrier for meaningful engagement of all relevant actors. 
Additionally, a broader deregulatory agenda and austerity measures since the 2008 economic crisis have had limited administrative capacity. This has led to the adoption of an approach largely build on soft measures and voluntary schemes based on incentives. De Vito et al. [16] conclude that, in order to be successful, the national government must play a central role in creating the right conditions. Governance structures should enable cooperation, balanced access to decision making and consistency. Adopting stricter regulatory measures is not only a function of the ambition of governments, but is also dependent on their ability to build consensus and overcome barriers and opposition.

The paper by Kirschke, Häger, Kirschke and Völker [17] focusses on Germany. The paper focusses on the efficacy of instrument mixes for resolving the problems of diffuse nitrate pollution. While not studying the effectiveness of instruments directly, they take the planning and implementation of measures as a proxy for behavioural change of farmers and of changing nutrient levels in freshwater sources. In their analysis of the German water policy, fertiliser policy and the national programme for the Common Agricultural Policy, the authors find low levels of coherency between those policy fields and limited diversity of the mobilised instruments. The German water policy is characterised by rules that comprise various exemptions for the agricultural sector. After the infringement procedure against Germany in 2013, the Fertiliser Regulation has become somewhat more stringent yet has been met with vehement protest by farmer's Rules. This has resulted in serious doubts regarding both the effectiveness and scientific underpinning of the new programme. The implementation of water-related measures under the second pillar of the Common Agricultural Policy in the different federal states has led to a mixed view. In sum, the resulting policy mix is dominated by rules and there has been little experimentation with economic incentives/disincentives and, to a lesser extent, with information and cooperation. This instrument mix has resulted in poor problem-solving. The paper concludes that a stronger integration of water and agricultural policies, as well as an increasing use of economic instruments via agricultural subsidies, are potential feasible routes to improve water quality.

The comparative paper by Wiering, Liefferink, Boezeman, Kaufmann, Crabbé and Kurstjens [18] describes the different governance approaches to nutrients and water of five member states and regions: The Netherlands, Flanders/Belgium, Lower Saxony/Germany, Denmark and Ireland. This paper focusses on the relationship between the general governance approach of a country and the nature of the measures and policy instruments chosen. The authors discern governance approaches on the dimensions of antagonism-consensus and integration-segregation. They use the concepts of source-based and effect-based as well as mandatory and voluntary to discern the nature of measures. Wiering and colleagues found a great variety in governance approaches, while, perhaps remarkably, the nature of measures, in terms of source-based and effect-based, is only slightly different. Voluntary programmes dominate the scene. Processes of professional mimicry and coercion by the European Commission are important explanations. On closer inspection, there are interesting differences in the consensual or antagonist discourses and differences in the use of more mandatory instruments or area-based policies. The authors conclude that in many countries, the major challenge is to strike a balance between taking source-based measures while addressing the economic consequences for farmers. Dealing with the wicked problem of diffuse pollution requires nuanced and tailor-made programmes of measures, perhaps combined with voluntary and incentive-based instruments, in vein of an experimentalist approach to governance. However, those experimentalist approaches come at the risk of not addressing nutrient pollution effectively or only doing so at high cost to taxpayer.

The contribution by Ptak, Graversgaard, Refsgaard and Dalgaard [19] provides an in-depth study of the factors that shape local level nitrate management discourses in Poland. The paper compares those findings to the policy process at the national level in Poland and Denmark to draw wider lessons on the factors that determine governance capacity and compliance performance. While classifying both countries as laggards in implementation performance of the WFD, the authors observe substantial differences in nitrate management discourses and the factors that explain those. The history of Denmark acts as a "front-runner" in nitrate management, resulting in a situation where the state is well-organised and resourced with the support of a political culture of compliance. The stagnation in progress in the 
last 15 years can be explained by the rise of an "over-implementation" narrative vis-à-vis other Member States in combination with increasing marginal costs resulting in political pressures to downscale ambitions. The Polish case, with its communist historical legacy, rather points to lacking capacities in both the state and non-state actors as an explanation for being able to fulfil EU obligations. The authors point at various factors that affect both fragmentation and insufficient organisational, cognitive and financial resources at different levels of the state and within the private sector. In addition, they stress the low willingness to give the aims of the WFD higher priority vis-a-vis the "core tasks" of agriculture to take care of food production. What stands out is a complex picture in which EU policies are accommodated, adjusted and contested.

\section{Conclusions}

The collected articles of this Special Issue present a state of the art of the governance approaches taken towards diffuse agricultural sources in different European Member States. What stands out in all these contributions is that governance approaches can be characterised by a mandatory basis that has its roots in the European Nitrates directive and an additional set of voluntary measures largely funded by budgets in the water policy domain as well as the national programmes of the Common Agricultural Policy, especially its second pillar.

What the collected articles of this Special Issue also bring to the fore is that measures taken under nitrate or fertiliser legislation seem to largely build upon groundwater concerns, which do not necessarily also translate to the need to achieve a good ecological status/potential in surface waters. The papers report that Denmark has set differentiated reduction targets and implementation measures for each watershed in accordance with the WFD, while the need to do this is also an important issue in the contemporary discourse in the Netherlands $[18,19]$. This signals serious concerns with policy integration across policy domains, the first main theme raised by Wiering et al. [14]. Both De Vito et al. [16] and Hovik [15] underline the importance of institutional structures facilitating cooperation, coordination and integration in early phases of policy development. Nevertheless, all studies highlight that the economic threats for, and interest politics lobby of, the agricultural sector lead to a separation of policy fields.

Although "prevention" and "polluter pays" are important principles of the WFD and of European environmental policy more generally, it appears to be tough to prioritise source-based measures (e.g., fertiliser policies, measures effecting the volume of animals and manure) over effect-based measures of all sorts. This relates to the second main theme of our Special Issue.

In various studies, scientific knowledge seems to be an important ally for water interests, yet, as e.g., Kirschke et al. [17] show, it is also overshadowed in power struggles. It is especially the shadow of hierarchy embodied by European Commission and its threats of infringement procedures that fuels revisions in mandatory measures, and the tightening of regulatory instruments, as three papers [17-19] illustrate.

Reflecting on the pathway of open, participatory and experimentalist governance that the WFD exemplifies, we have to raise serious doubts about the effectiveness of policies when it comes to this "wicked problem" of agricultural diffuse pollution. Most authors agree that this path is attractive and appropriate in some respects, but more effective measures are to be expected when stricter structural policies for the agricultural domain are applied. Participatory, experimental governance avoids confrontations with the sector, but comes with general societal costs.

The papers in this collection have largely focused on the issue of nutrients in different parts of Europe, with an emphasis on Northwestern European Member States. This collection adds to the comparative understanding of effective policy approaches that is needed now that countries are on the verge of the last round of river basin management plans under the Water Framework Directive. Nevertheless, beyond 2027 diffuse agricultural sources will remain a "wicked problem" for governance and new issues will emerge. This underscores the salience of understanding effective governance 
approaches and raises new questions how those approaches might differ for Member States in the southern and, except for Poland, eastern parts of Europe.

Author Contributions: M.W., D.B. and A.C. all contributed to the conceptualisation and editing of this Special Issue. D.B., M.W. and A.C. all contributed to the manuscript of the editorial. All authors have read and agreed to the published version of the manuscript.

Funding: This research received no external funding.

Conflicts of Interest: The authors declare no conflict of interest.

\section{References}

1. Van Rijswick, H.; Backes, C.W. Ground breaking landmark case on environmental quality standards? J. Eur. Environ. Plan. Law 2015, 12, 363-377. [CrossRef]

2. Kristensen, P.; Whalley, C.; Klancnik, K. European Waters: Assessment of Status and Pressures 2018; European Environmental Agency: Copenhagen, Denmark, 2018.

3. Carvalho, L.; Mackay, E.B.; Cardoso, A.C.; Baattrup-Pedersen, A.; Birk, S.; Blackstock, K.L.; Borics, G.; Borja, A.; Feld, C.K.; Ferreira, M.T.; et al. Protecting and restoring Europe's waters: An analysis of the future development needs of the Water Framework Directive. Sci. Total Environ. 2019, 658, 1228-1238. [CrossRef] [PubMed]

4. European Commission. European Commission Report from the Commission to the European Parliament and the Council on the Implementation of the Water Framework Directive (2000/60/EC) and the Floods Directive (2007/60/EC). COM 95 Final; European Commission: Brussels, Belgium, 2019.

5. Jager, N.; Challies, E.; Kochskämper, E.; Newig, J.; Benson, D.; Blackstock, K.L.; Collins, K.; Ernst, A.; Evers, M.; Feichtinger, J.; et al. Transforming European water governance? Participation and river basin management under the EU Water Framework Directive in 13 member states. Water 2016, 8, 156. [CrossRef]

6. Kochskämper, E.; Challies, E.; Newig, J.; Jager, N. Participation for effective environmental governance? Evidence from Water Framework Directive implementation in Germany, Spain and the United Kingdom. J. Environ. Manag. 2016, 181, 737-748. [CrossRef]

7. Liefferink, D.; Wiering, M.; Uitenboogaart, Y. The EU Water Framework Directive: A multi-dimensional analysis of implementation and domestic impact. Land Use Policy 2011, 28, 712-722. [CrossRef]

8. Maia, R. The WFD implementation in the European member states. Water Resour. Manag. 2017, 31, 3043-3060. [CrossRef]

9. Boeuf, B.; Fritsch, O.; Martin-Ortega, J. Undermining European environmental policy goals? The EU Water Framework Directive and the politics of exemptions. Water 2016, 8, 388. [CrossRef]

10. Jacobsen, B.H.; Anker, H.T.; Baaner, L. Implementing the water framework directive in Denmark-Lessons on agricultural measures from a legal and regulatory perspective. Land Use Policy 2017, 67, 98-106. [CrossRef]

11. Craig, R.K.; Roberts, A. When Will Governments Regulate Nonpoint Source Pollution? A Comparative Perspective. BC Envtl. Aff. L. Rev. 2015, 42, 1-64.

12. Daugbjerg, C.; Roederer-Rynning, C. The EU's Common Agricultural Policy: A case of defensive policy import. In EU Policies in a Global Perspective: Shaping or Taking International Regimes? Falkner, G., Muller, P., Eds.; Routledge: London, UK, 2014; pp. 38-57.

13. Vermeulen, J.; Whiteoak, K.; Nicholls, G.; Gerber, F.; McAndrew, K.; Cherrier, V.; Cunningham, E.; Kirhensteine, I.; Wolters, H.; Verweij, W. Fitness Check Evaluation of the Water Framework Directive and the Floods Directive: Final Evaluation Report; European Commission, Directorate-General for Environment: Brussels, Belgium, 2019.

14. Wiering, M.; Boezeman, D.; Crabbé, A. The Water Framework Directive and agricultural diffuse pollution: Fighting a running battle? Water 2020, 12, 1447. [CrossRef]

15. Hovik, S. Integrated water quality governance and sectoral responsibility: The EU Water Framework Directive's impact on agricultural sector policies in Norway. Water 2019, 11, 2215. [CrossRef]

16. De Vito, L.; Fairbrother, M.; Russel, D. Implementing the Water Framework Directive and tackling diffuse pollution from agriculture: Lessons from England and Scotland. Water 2020, 12, 244. [CrossRef]

17. Kirschke, S.; Häger, A.; Kirschke, D.; Völker, J. Agricultural nitrogen pollution of freshwater in Germany. The governance of sustaining a complex problem. Water 2019, 11, 2450. [CrossRef] 
18. Wiering, M.; Liefferink, D.; Boezeman, D.; Kaufmann, M.; Crabbé, A.; Kurstjens, N. The wicked problem the water framework directive cannot solve. The Governance approach in dealing with pollution of nutrients in surface water in the Netherlands, Flanders, Lower Saxony, Denmark and Ireland. Water 2020, 12, 1240. [CrossRef]

19. Ptak, E.N.; Graversgaard, M.; Refsgaard, J.C.; Dalgaard, T. Nitrate management discourses in Poland and Denmark-Laggards or leaders in water quality protection? Water 2020, 12, 2371. [CrossRef] 